Research Article

\title{
Awareness of Tuberculosis and RNTCP among Interns at a Tertiary Care Hospital in Goa
}

\author{
Mahika Virendra Naik', Anika Anil Prabhu Parrikar ${ }^{2}$, Jagadish Anil Cacodcar ${ }^{3}$ \\ ${ }^{1}$ Post Graduate Student and Junior Resident, Department of Preventive and Social Medicine, Goa Medical College, Goa, India. \\ ${ }^{2} \mathrm{MD}$, Senior Resident, Department of Pulmonary Medicine, Goa Medical College, Goa, India. \\ ${ }^{3} \mathrm{MD}$, Professor and Head, Department of Preventive and Social Medicine, Goa Medical College, Goa, India. \\ DOI: https://doi.org/10.24321/2455.7048.202019
}

$\begin{array}{llll}\text { I } & \mathbf{N} & \mathbf{F} & \mathbf{O}\end{array}$

\section{Corresponding Author:}

Anika Anil Prabhu Parrikar, Department of Pulmonary Medicine, Goa Medical College, Goa, India.

E-mail Id:

anikaparrikar@gmail.com

Orcid Id:

https://orcid.org/0000-0002-5620-1149

How to cite this article:

Naik MV, Parrikar AAP, Cacodcar JA. Awareness of Tuberculosis and RNTCP among Interns at a Tertiary Care Hospital in Goa. Epidem Int 2020; 5(3): 1-5.

Date of Submission: 2020-02-18

Date of Acceptance: 2020-05-19

\section{$\begin{array}{lllllllll}\mathbf{A} & \mathbf{B} & \mathbf{S} & \mathbf{T} & \mathbf{R} & \mathbf{A} & \mathbf{C} & \mathbf{T}\end{array}$}

Introduction: India is the highest burdened country with Tuberculosis (TB) bearing over one fourth of the global TB burden. HIV and drug resistance have further complicated the scenario. Thorough knowledge about TB, its diagnosis and treatment as well as about HIV-TB and drug resistance is needed to make RNTCP and TB control a success.

Materials \& Methods: A cross sectional study was conducted among 90 medical interns who answered a self-administered semi structured questionnaire consisting of 30 questions, answered over 30 minutes, conducted over a 3-month period from July to September 2019. Data was entered in MS Excel and analysed using SPSS 14.0 software. Results were expressed in percentages and proportions. $P$ value $<0.05$ was considered as statistically significant.

Result: The response rate was $100 \%$. Mean age of interns was 23 to 25 years with $56.6 \%$ of them being females. $98.8 \%$ of the interns correctly identified the chief symptom of TB. $90 \%$ of them knew the role of DOTS centre in TB control. However, the overall knowledge regarding HIV-TB and Drug resistant TB was poor. None of them had received prior RNTCP training.

Conclusion: Our study has identified several gaps in the knowledge among medical interns in Goa regarding various aspects of TB diagnosis, RNTCP, HIV-TB and Drug resistant TB. RNTCP training and sensitization must be a mandatory part of the interns training to improve the control of TB in India.

Keywords: Knowledge, Awareness, RNTCP, Tuberculosis, Medical Interns

\section{Introduction}

As per the Global TB report 2019, ${ }^{1}$ there are nearly 10 million new cases of TB worldwide in 2018, with more than one fourth of the burden (27\%) being contributed by
India. ${ }^{2}$ Globally, there were 1.2 million TB deaths amongst HIV negative and an additional 0.25 million deaths among HIV positive individuals. Nearly half a million new cases of drug resistant TB were diagnosed worldwide (of which 
$78 \%$ had MDR TB), with $27 \%$ being contributed by India. ${ }^{1}$

RNTCP after being formally launched in 1992, has attained nationwide coverage in a phased manner by 2005 with the help of WHO recommended DOTS strategy. ${ }^{6}$ Information, Education and Communication (IEC) are an important strategy of the program to create awareness among public, health care providers and policy makers. Despite all this, India continues to be the highest TB burdened country in the world.

Inappropriate and incomplete prescription and treatment leads to the development and spread of TB and drug resistance. ${ }^{8}$ Lack of knowledge and awareness of TB among medical students, interns, doctors in the private sector and other health care personnel further contributes to the poor disease control in the country. Internship is one of the most crucial periods in the training curriculum of a doctor, when a student acquires new skills and applies theoretical knowledge into clinical practice. ${ }^{3}$

\section{Objective}

To assess the level of awareness among medical interns at a tertiary care hospital, of the various aspects of DOTS \& RNTCP towards the diagnosis and treatment of TB, including drug resistant TB.

\section{Materials and Methods}

A cross sectional study was conducted among 90 medical interns of Goa Medical College, the only tertiary care hospital in Goa during July - September 2019. Census method of sampling was followed. A semi-structured predesigned questionnaire was self-administered to the study participants. This questionnaire had thirty questions in English language pertaining to the diagnosis and treatment of TB, basic knowledge about RNTCP, TB-HIV and drug resistant TB. The interns were given a period of 30 minutes to complete the questionnaire under the investigators supervision after obtaining their informed written consent to participate in the study. All MBBS interns (2019-2020 Batch) who consented to participate in the study were included, whereas those interns who either declined consent or who were unavailable despite multiple attempts made by the study investigators to contact them twice, were excluded from the study. The data was collected after ensuring confidentiality. Prior approval was obtained from the Institutional Ethics Committee.

\section{Statistical Analysis}

The data was entered in MS Excel and analysed using SPSS 14.0 software. The results were expressed in simple percentages and proportions.

\section{Result}

A total of 90 interns participated in the study, of which $43.3 \%$ $(n=39)$ were males and over half i.e. $56.6 \%(n=51)$ were females. Their ages varied from 23 to 25 years. Surprisingly, none of the interns interviewed received RNTCP training during or at commencement of their internship. The responses by the study participants are provided in the tables below.

More than half of the interns (55.5\%) correctly identified the objectives of RNTCP pertaining to case detection and cure. Nearly $94.4 \%$ of them were aware that TB is a notifiable disease. Also, $98.8 \%$ of the interns identified cough as the predominant symptom of TB.

Nearly $91.1 \%$ of the interns correctly knew the definition of sputum smear positive pulmonary TB, but the overall knowledge of the interns about RNTCP and DOTS was poor.

Nearly $90 \%$ of the interns were aware of the six months duration of TB treatment for new cases and also that culture was the gold standard test for TB diagnosis. $92 \%$ of them correctly identified the bactericidal anti TB drugs from the options provided.

Table I.Awareness about objectives of RNTCP \& basic knowledge of TB

\begin{tabular}{|c|c|c|c|}
\hline & $\begin{array}{c}\text { Correct response } \\
\mathbf{n}(\%)\end{array}$ & $\begin{array}{c}\text { Incorrect response } \\
\mathbf{n}(\%)\end{array}$ & $\begin{array}{c}\text { Total number } \\
\text { (\%) }\end{array}$ \\
\hline Identified case detection and cure rate objectives \\
of RNTCP & $50(55.5 \%)$ & $40(45.5 \%)$ & $90(100 \%)$ \\
\hline $\begin{array}{c}\text { Identified cough as chief symptom of presumptive } \\
\text { PTB }\end{array}$ & $89(98.8)$ & $1(1.2 \%)$ & $90(100 \%)$ \\
\hline $\begin{array}{c}\text { Lifetime risk of developing TB disease in PPD } \\
\text { positive, HIV negative persons }\end{array}$ & $32(35.5 \%)$ & $58(65.5)$ & $90(100 \%)$ \\
\hline TB being a notifiable disease & $85(94.4 \%)$ & $5(5.6 \%)$ & $90(100 \%)$ \\
\hline Whether BCG provides full protection against PTB & $17(18.8 \%)$ & $73(81.2 \%)$ & $90(100 \%)$ \\
\hline Knowledge about latent TB infection & $26(28.8 \%)$ & $54(62.2 \%)$ & $90(100 \%)$ \\
\hline
\end{tabular}


Table 2.Knowledge about RNTCP and DOTS

\begin{tabular}{|c|c|c|c|}
\hline & Correct response $\mathbf{n}(\%)$ & Incorrect response $\mathbf{n}(\%)$ & Total number (\%) \\
\hline Stated definition of a "New case" of TB & $15(16.6 \%)$ & $75(84.4 \%)$ & $90(100 \%)$ \\
\hline $\begin{array}{c}\text { Stated smear positive pulmonary TB case } \\
\text { definition }\end{array}$ & $82(91.1 \%)$ & $8(8.9 \%)$ & $90(100 \%)$ \\
\hline $\begin{array}{c}\text { Identified reagents used in Ziehl Neelsen } \\
\text { Staining for AFB }\end{array}$ & $11(12.2 \%)$ & $79(87.8 \%)$ & $90(100 \%)$ \\
\hline Identified role of DOTS centre & $88(97.7 \%)$ & $12(2.3 \%)$ & $90(100 \%)$ \\
\hline $\begin{array}{c}\text { Awareness regarding Designated } \\
\text { Microscopy Centres (DMCs) }\end{array}$ & $10(11.1 \%)$ & $80(88.9 \%)$ & $90(100 \%)$ \\
\hline $\begin{array}{c}\text { Identification of sputum criteria for AFB } \\
\text { Smear testing }\end{array}$ & $73(81.1 \%)$ & $17(18.9 \%)$ & $90(100 \%)$ \\
\hline $\begin{array}{c}\text { Awareness about sub-district level } \\
\text { supervisory unit (TU) under RNTCP }\end{array}$ & $8(8.8 \%)$ & $82(91.2 \%)$ & $90(100 \%)$ \\
\hline $\begin{array}{c}\text { Whether family member can be DOTS } \\
\text { provider }\end{array}$ & $16(17.7 \%)$ & $74(82.3 \%)$ & $90(100 \%)$ \\
\hline
\end{tabular}

Table 3.Awareness about diagnosis and treatment of TB

\begin{tabular}{|c|c|c|c|}
\hline & Correct response $\mathbf{n}(\%)$ & Incorrect response $\mathbf{n}(\%)$ & Total number (\%) \\
\hline $\begin{array}{c}\text { Knowledge of the TB treatment regimen } \\
\text { for new cases }\end{array}$ & $81(90 \%)$ & $9(10 \%)$ & $90(100 \%)$ \\
\hline Identification of bactericidal anti-TB drugs & $83(92.2 \%)$ & $7(7.8 \%)$ & $90(100 \%)$ \\
\hline $\begin{array}{c}\text { Awareness of TB treatment duration for } \\
\text { previously treated patients }\end{array}$ & $14(15.5 \%)$ & $76(84.5 \%)$ & $90(100 \%)$ \\
\hline $\begin{array}{c}\text { Identified gold standard test for TB } \\
\text { diagnosis }\end{array}$ & $81(90 \%)$ & $9(10 \%)$ & $90(100 \%)$ \\
\hline $\begin{array}{c}\text { Knowledge of hepatotoxicity of most anti- } \\
\text { TB drugs }\end{array}$ & $8(8.8 \%)$ & $82(91.2 \%)$ & $90(100 \%)$ \\
\hline $\begin{array}{c}\text { Knowledge of the preferred test for } \\
\text { diagnosis of EPTB }\end{array}$ & $11(12.2 \%)$ & $79(87.8 \%)$ & $90(100 \%)$ \\
\hline
\end{tabular}

Table 4.Awareness about TB in HIV patients and pregnant females

\begin{tabular}{|c|c|c|c|}
\hline & Correct response $\mathbf{n}(\%)$ & Incorrect response $\mathbf{n}(\%)$ & Total number (\%) \\
\hline $\begin{array}{c}\text { Identified anti TB drugs contraindicated in } \\
\text { pregnancy }\end{array}$ & $15(16.6 \%)$ & $75(84.4 \%)$ & $90(100 \%)$ \\
\hline $\begin{array}{c}\text { Awareness of role of co-trimoxazole in } \\
\text { mortality reduction in TB-HIV patients }\end{array}$ & $5(5.5 \%)$ & $85(94.5 \%)$ & $90(100 \%)$ \\
\hline $\begin{array}{c}\text { Whether pregnant TB mothers can } \\
\text { breastfeed }\end{array}$ & $80(88.8 \%)$ & $10(11.2 \%)$ & $90(100 \%)$ \\
\hline $\begin{array}{c}\text { Lifetime risk of developing TB disease in } \\
\text { HIV+ persons who are PPD positive }\end{array}$ & $3(3.3 \%)$ & $87(96.7 \%)$ & $90(100 \%)$ \\
\hline $\begin{array}{c}\text { Knowledge about 99-DOTS for TB-HIV } \\
\text { patients }\end{array}$ & $18(20 \%)$ & $72(80 \%)$ & $90(100 \%)$ \\
\hline
\end{tabular}

The knowledge of TB in HIV and pregnant females was poor except that $88 \%$ of the interns were aware that pregnant TB females can breastfeed.
$83 \%$ of the interns correctly knew the definition of MDR-TB. Just over half of the interns were aware of the full form of CBNAAT and that it has no role in follow up of TB treatment. 
Table 5.Knowledge of newer advances in TB and MDR-TB

\begin{tabular}{|c|c|c|c|}
\hline & Correct response $\mathbf{n}(\%)$ & Incorrect response $\mathbf{n}(\%)$ & Total number (\%) \\
\hline $\begin{array}{c}\text { Identified full form of CB NAAT } \\
\text { Identified Bedaquiline as new drug for } \\
\text { MDR TB treatment }\end{array}$ & $46(51.1 \%)$ & $44(48.9 \%)$ & $90(100 \%)$ \\
\hline $\begin{array}{c}\text { Identified case definition of MDR-TB } \\
\begin{array}{c}\text { Whether CB NAAT has a role in follow up } \\
\text { assessment of TB patients }\end{array}\end{array}$ & $51(25.5 \%)$ & $15(16.7 \%)$ & $90(100 \%)$ \\
\hline
\end{tabular}

\section{Discussion}

\section{Basic Knowledge of TB and RNTCP}

Majority i.e. $94.4 \%$ of the interns were aware that TB is a notifiable disease. Our finding was similar to a study by Abdurehiman T et al. ${ }^{4}$ ( $85 \%$ ) but unlike the study by Chennaveerappa $\mathrm{K}$ et al. ${ }^{3}$, where only $42.9 \%$ reported that TB is a notifiable disease. Almost all our interns (98.8\%) were aware of the chief symptom of PTB. However, in some studies by Sangma et al. $^{5}(75.2 \%)$ and Basu M, Das $\mathrm{P}^{6}(65.4 \%)$, the awareness regarding the same was much lesser. Only $55 \%$ of the interns knew the objectives of RNTCP similar to Basu M, Das $\mathrm{P}^{6}(51.3 \%)$ and Baveja SM, Dalal PJ. ${ }^{7}$ (55.8\%). Overall knowledge about basic facts of TB including latent TB infection (LTBI) was very low. Only $18.8 \%$ were aware that BCG does not confer full protection against PTB, in contrast to a study finding by Chennaveerappa $\mathrm{K}$ et al. ${ }^{3}(96.9 \%)$.

\section{Knowledge of RNTCP \& DOTS}

Majority of the interns were aware of the criteria for sputum diagnosis of TB (81.1\%). Our finding was similar to study by Patel RA et al. $(88.23 \%)^{8}$ and Chennaveerappa K et al. ${ }^{3}$ (83.2\%). However, in studies by Basu M, Das $\mathrm{P}^{6}$, and Sangma BK et al. ${ }^{5}$, only $21.8 \%$ \& $45.5 \%$ of the interns respectively were aware of the criteria for sputum diagnosis for TB. Most interns in our study (91.1\%), were aware of the correct definition of smear positive pulmonary TB and majority of them $(97.7 \%)$ correctly identified the various roles of a DOTS centre. However, the knowledge regarding the definition of a 'new case' of TB under RNTCP was very poor among interns (16.6\%) which was much lesser than that reported in a study by Sangma BK et al. ${ }^{5}(45.9 \%)$. Only $12.2 \%$ of the interns were aware of the various reagents used in Ziehl Neelsen staining, which was very low as compared to study by Chennaveerappa K et al. ${ }^{3}(61.5 \%)$. The knowledge regarding family member as a DOT provider was poor with only $17.7 \%$ having correctly answered; almost similar to the observation in their study by Chennaveerappa $\mathrm{K}$ et al. $^{3}(37.3 \%)$.

\section{Awareness regarding TB Diagnosis and Treatment}

Most interns in our study (90\%) could correctly identify the treatment regimen for new TB patients, unlike study finding by Balamurugan SS et al. ${ }^{8}$ (48.7\%). However, only $15.5 \%$ of patients were aware of the latest RNTCP recommended duration of treatment for previously treated TB patients. This was probably due to the lack of awareness among interns about the newer changes and updates in TB treatment guidelines by RNTCP. The non-hepatotoxic drug among the options provided was correctly identified by only $8.8 \%$ interns, which was very low in contrast to study by Balamurugan SS et al. ${ }^{8}(50.9 \%)$ and Abdurehiman T et al. ${ }^{4}(60 \%)$. However, as few as $12.2 \%$ of the interns were aware of CB NAAT as a preferred diagnostic tool for extrapulmonary TB (EPTB), despite the test being available at our Hospital.

\section{Knowledge regarding TB in Pregnancy and HIV Patients}

Only $16.6 \%$ of the interns were aware of streptomycin being contraindicated in pregnancy. This was in contrast to studies by Sangma BK et al. ${ }^{5}(72 \%)$ and Chennaveerappa $\mathrm{K}$ et al. $^{3}(72.7 \%)$. Majority of them were aware $(88.8 \%)$ that breastfeeding is not contraindicated in pregnant TB patients, which was higher than that reported by Chennaveerappa $\mathrm{K}$ et al. ${ }^{3}(68.8 \%)$. Majority of the interns $(94.5 \%)$ were unaware of use of co-trimoxazole as a part of TB-HIV mortality reduction. So also, the knowledge regarding the 99-DOTS for TB-HIV co-infected patients and the lifetime risk of TB in HIV patients with PPD positivity was very poor.

\section{Awareness of Recent Advances in TB and MDR TB}

$83.3 \%$ of the interns in the study correctly identified the definition of MDR-TB. Our finding was similar to some studies by K Chennaveerappa et al. ${ }^{3}(77.6 \%)$, Sangma et al. ${ }^{5}$ (84.2\% ) and Basu M, Das $\mathrm{P}^{6}(91 \%)$. It was disheartening to note that only one fourth of the interns (25.5\%) were aware of Bedaquiline as a new drug for MDR-TB. Also, only over half of the interns knew the acronym of CB NAAT correctly, and could identify that CB NAAT cannot be used as a TB follow up assessment tool.

\section{Conclusion}

This study reveals that the knowledge of the medical interns was good about TB being a notifiable disease, the chief 
symptom of TB, the sputum criteria for pulmonary TB diagnosis and the new duration of treatment recommended by RNTCP for previously treated patients. So also, the definition of MDR TB was correctly known by most of the interns. Majority of interns knew that breastfeeding is not contraindicated, but we're unaware that streptomycin is contraindicated in pregnancy. However, the interns had poor knowledge regarding LTBI, adverse effects of anti TB drugs, the latest approved drug bedaquiline for drug resistant TB, TB HIV and CB NAAT. Our study highlights the need for RNTCP training of medical interns to make TB control and RNTCP a success, as they are going to be the future resident doctors, specialists or medical practitioners.

\section{Conflict of Interest: None Declared}

\section{References}

1. Global Tuberculosis Report 2019, Geneva: World Health Organization; 2019. Licence: CCBY-NC-SA3. olGO accessed on 20.02.2020.

2. Annual Report: India TB Report 2019 Central TB Division, available at www.tbcindia.gov.in accessed on 20.02.2020.

3. Chennaveerappa K, Rajashekar HK, Nagaral J et al. A study on awareness of tuberculosis and RNTCP among undergraduate medical students and interns. Journal of Evolution of Medical and Dental Sciences 2014; 3: 8115-8121.

4. Abdurehiman T, Krishnappriya Ramachandran, Arun Prasath $R$ et al. To assess the awareness and knowledge of pulmonary tuberculosis and RNTCP among interns and postgraduates at a tertiary care hospital in South India. Paripex - Indian Journal of Research 2018; 7(1): 14-16.

5. Sangma BK, Bhavya S, Sinh WA et al. Assessment of knowledge on management of pulmonary tuberculosis under RNTCP among graduating interns and postgraduate students in RIMS Imphal. IOSR Journal of Nursing and Health Science 2017; 6(3): 07-11.

6. Basu M, Das P. Assessment of knowledge regarding tuberculosis in the context of revised national tuberculosis control program among budding doctors. Chronicles of Young Scientists 2014; 5(1): 59-64.

7. Baveja SM, Dalal PJ. Awareness of the revised National Tuberculosis Control Programme and attitude to tuberculosis patients amongst medical undergraduates. Journal of Academy of Medical Sciences 2012; 2(2): 68-72.

8. Balamurugan SS, Rao S. The awareness about tuberculosis and dots among the aspiring doctors in a tertiary medical college hospital, Salem, Tamil Nadu. National J Res Community Med 2013; 2(2): 79-148. 